\title{
Prospective randomized controlled trial (phase III) to comparing laparoscopic distal gastrectomy with open distal gastrectomy for gastric adenocarcinoma (KLASS 01)
}

\begin{abstract}
Hyung-Ho Kim, Sang-Uk Han', Min-Chan Kim², Woo Jin Hyung³, Wook Kim4, Hyuk-Joon Lee ${ }^{5}$, Seung Wan Ryu', GyuSeok Cho ${ }^{7}$, Chan Young Kim ${ }^{8}$, Han-Kwang Yang ${ }^{5}$, Do Joong Park, Kyo Young Song ${ }^{9}$, Sang IL Lee ${ }^{10}$, Seong Yeob Ryu ${ }^{11}$, Joo Ho Lee ${ }^{12}$; Korean Laparoscopic Gastrointestinal Surgery Study (KLASS) Group

Department of Surgery, Seoul National University Bundang Hospital, Seoul National University College of Medicine, Seongnam, ${ }^{1}$ Department of Surgery, Ajou University School of Medicine, Suwon, ${ }^{2}$ Department of Surgery, Dong-A University College of Medicine, Busan, ${ }^{3}$ Department of Surgery, Institute of Gastroenterology, Yonsei University College of Medicine, Seoul, ${ }^{4}$ Department of Surgery, Yeouido St. Mary's Hospital, The Catholic University of Korea College of Medicine, Seoul, ${ }^{5}$ Department of Surgery, Cancer Research Institute, Seoul National University, Seoul, ' ${ }^{6}$ Department of Surgery, Keimyung University School of Medicine, Daegu, 'Department of Surgery, Soonchunhyang University Bucheon Hospital, Soonchunhyang University College of Medicine, Bucheon, ${ }^{8}$ Department of Surgery, Chonbuk National University Hospital, Jeonju, ${ }^{9}$ Department of Surgery, Seoul St. Mary's Hospital, The Catholic University of Korea College of Medicine, Seoul, ${ }^{10}$ Department of Surgery, Chungnam National University Hospital, Daejeon, ${ }^{11}$ Department of Surgery, Chonnam National University Medical School, Gwangju, ${ }^{12}$ Department of Surgery, Ewha Womans University Mokdong Hospital, Seoul, Korea
\end{abstract}

http://dx.doi.org/10.4174/jkss.2013.84.2.123

J Korean Surg Soc 2013;84(2):123-30

\section{To the Editor}

Thank you for publication our clinical trial note entitled "Prospective randomized controlled trial (phase III) to comparing laparoscopic distal gastrectomy with open distal gastrectomy for gastric adenocarcinoma (KLASS 01)" in volume 84(2) of the February 2013 issue. In the original publication, we created several mistakes in the number of the recruited patients and the participating institutions. Thus those were described as 1,415 patients (704 underwent LADG and 711 underwent ODG) and 12 institutions in the abstract, Study setting, Progress and
Fig. 1 when submitted to the publisher. These mistakes were not due to the editorial office of Journal of the Korean Surgical Society. We attached an erratum along with this letter to request for corrections; (1) 1,415 patients into 1,416 patients, (2) '704 underwent LADG and 711 underwent ODG' into ' 705 were assigned to LADG and 711 were assigned to ODG', and (3) 12 institutions into 13 institutions.

Sincerely yours,

Hyung-Ho Kim 


\section{Corrected Figure}

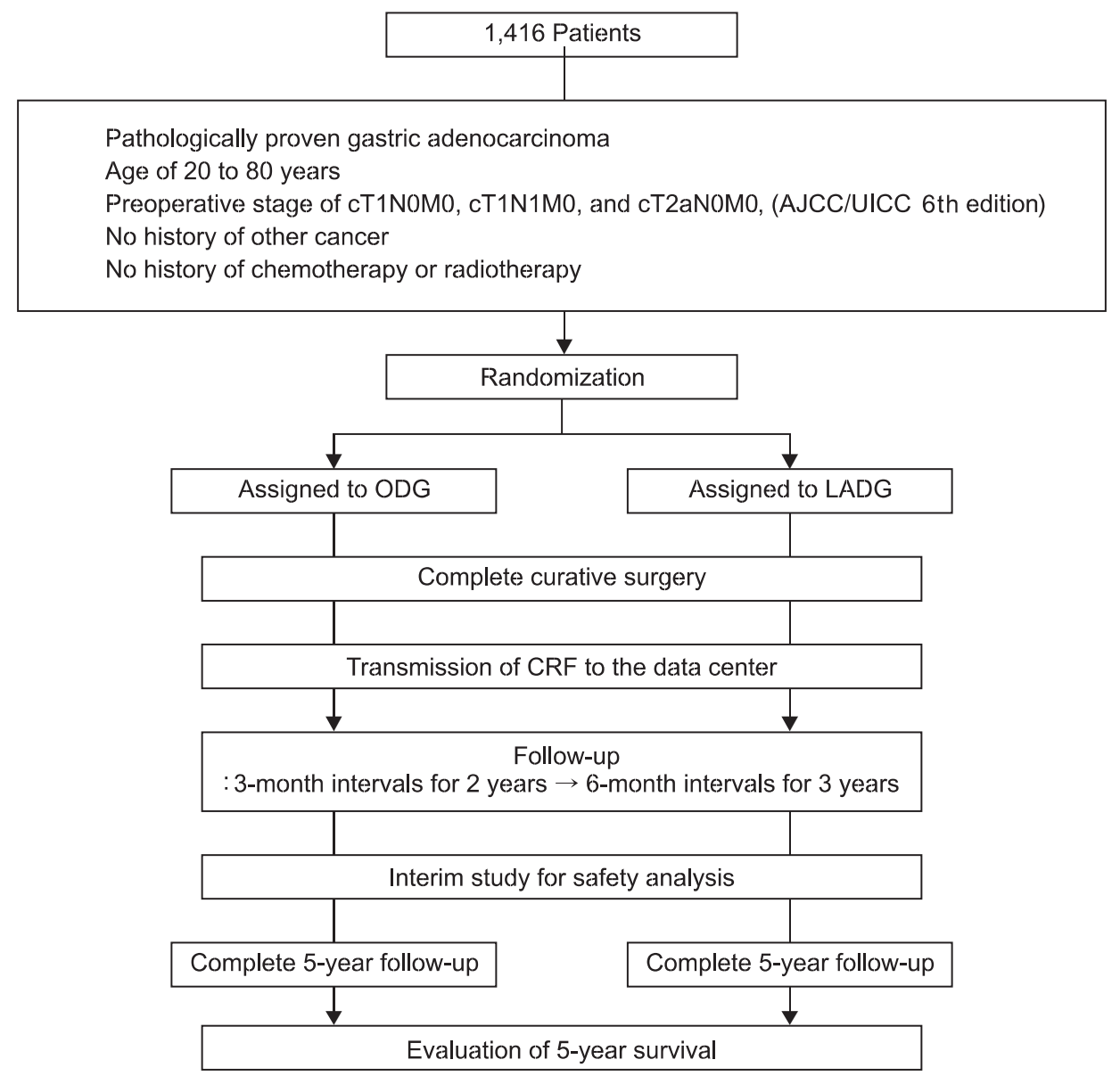

Fig. 1. Scheme diagram of the study. AJCC/UICC, American Joint Committee on Cancer/Union for International Cancer control; ODG, open distal gastrectomy; LADG, laparoscopy-assisted distal gastrectomy; CRF, case report form. 